\title{
Processing of Polyurethane Nanocomposite Reinforced with Nanosized Zinc Oxide: Effect on Mechanical and Acoustic Properties
}

\author{
Soma A. EI Mogy ${ }^{1^{*}}$, Rabab S. Youssef ${ }^{2}$, Anhar A. Abd El Megeed ${ }^{1}$ \\ ${ }^{1}$ Polymer Metrology and Technology Department, National Institute of Standards \\ (NIS), Egypt. \\ ${ }^{2}$ Acoustic Department, National Institute of Standards (NIS), Egypt.
}

\begin{abstract}
JANOSTRUCTURED materials are an important subject in different applications. Zinc oxide $(\mathrm{ZnO})$ nanoparticles have much attention because of their unique properties. The objective of this work is to synthesise zinc oxide nanoparticles by simplest chemical method (direct aqueous precipitation). Also, the effect of zinc oxide addition to polyurethane foam (PUF) on the mechanical and sound properties has been evaluated. Different concentrations of $\mathrm{ZnO}(0.25,0.5,1,2$ and $3 \mathrm{wt} . \%)$ were used. $\mathrm{ZnO}$ nanoparticles were characterized by some techniques such as X-Ray diffraction, Energy dispersive X-ray spectrometry and Transmission electron microscopy analysis. Scanning electron microscope was used to describe the dispersion state of the nanoparticles in the polyurethane foam. Density of PUF increased while the particle size decreased. Finally, it was confirmed that the mechanical and acoustic properties of polyurethane nanocomposites were improved and depend on the amount of nanozinc oxide.
\end{abstract}

Keywords: Synthesis, Nano Zinc oxide, Polyurethane, Mechanical, Acoustic.

\section{Introduction}

Nano reinforcing particles have high aspect ratio (surface/area ratio) and low density. So, they were used as substitutes for traditional fillers in polymer composites. $\mathrm{ZnO}$ nanoparticles attracted much attention from polymer scientists. $\mathrm{ZnO}$ nanoparticles are the most one studied among the nanoparticles because of their fundamental study and applications in gas sensors, solar energy, luminescence, transparent UV protection films, photocatalytic, and chemical sensors [1,2]. Several methods have been developed for synthesis of nanomaterial such as thermal decomposition, solgel, chemical vapor deposition, spray-pyrolysis, and precipitation method $[3,4]$. The precipitation technique compared with other methods is the best method, which does not need expensive materials and complicated equipment.

Polyurethane foams (PUF) are widely used in transportation, building and structural applications. Besides their versatility, polyurethanes have moderate price. The specific properties of PUF can be varied according to the type of preparation technique, raw materials, density, and method of applications. Polyurethanes are a class of polymers that contains a urethane linkage $(-\mathrm{NH}-\mathrm{CO}-\mathrm{O}-)$ that created by the reaction between diisocyanates and polyhydroxy (polyol) compound that contains active hydrogen. When water is used as blowing agent, carbon dioxide is the by-product.

Nowadays, noise pollution has become one of the most important serious issues in our society. There are a lot of studies which clarify the effect of noise on human health and wellbeing. The exposure to high noise can lead to a range of physical problems such as high blood pressure, heart beats and less concentration. So, we are in a need for a noise control and there are different ways to reduce noise pollution, one of these ways is using sound damping material. Polymeric materials are usually used, which dissipate the sound or the vibrational mechanical energy into heat energy [6,7]. Polymeric foams are important and versatile materials due to their outstanding strength to weight ratio, their resilience and their electrical, thermal and acoustic insulating properties amongst other characteristics [8]. Polyurethane is one of the largest and most versatile families of polymers.

"Corresponding author e-mail: soma.elmogy@yahoo.com; Tel.: +201285483139

DOI:10.21608/EJCHEM.2018.4655.1410

C2017 National Information and Documentation Center (NIDOC) 
The physical properties of PU are derived from their molecular structure caused by interactions between the polymer chains. The segmental flexibility, the chain entanglement, and the crosslinkage influence the properties and determine the use of the end products. The modification of PU using different nanofillers improves its properties. Several studies were introduced to improve the properties of polyurethane foam. One was used calcite and dolomite to influence the mechanical properties of polyurethane foam [9]. Nanolayered silicate has been used as a filler in poly(urethaneurea) composite resulting in significant increase of mechanical properties [10]. Some researchers illustrated that the addition of small amount of organoclay was enough to improve thermal and mechanical properties of PU [11]. Liliane et al found that addition of small amounts of montmorillonite carbon nanotube hybrids enhanced the properties of PUF nanocomposites [12]. Cigdem studied PUF reinforced by carbon nanotube and nanosilica to enhance flexural strength of foam cored sandwich composites [13]. On the other hand, Benni et al studied the fabrication of rigid PU/ nanoclay/carbon nanotube without modification and concluded that nanofillers especially nanoclay act as nucleating agent for PU matrix [14].

Few reports are available on the influence of $\mathrm{ZnO}$ nanofiller on the PUF, but there is no data to define the ideal quantity of nano zinc oxide that should be added without causing damage to the mechanical and acoustic properties of the final product. Thus, the proposal of the present work was to analyze the morphological, mechanical and sound behaviors when various concentrations of $\mathrm{ZnO}$ nanoparticles were introduced into the PU matrix. The uncertainty of all properties was evaluated.

\section{Material and Methods}

\section{Experimental}

Zinc nitrate was purchased from Alfa chemical, India. It has molecular formula $\mathrm{Zn}\left(\mathrm{NO}_{3}\right)_{2} 6 \mathrm{H}_{2} \mathrm{O}$. Its molecular weight is 297.48 . Urea was purchased from Ardwick (El-Nasr Pharmaceutical Chemicals Company, Egypt). To produce polyurethane and polyurethane nanocomposite foams, diisocyanate and polyol were provided from local company, Egypt. Distilled water was generated from our laboratory and was used as a blowing agent. All materials were used without further purification.
Nano zinc oxide preparation

Zinc oxide nanoparticles were prepared from aqueous solutions of zinc nitrate-6-hydrate, and urea [15]. Urea solution was acted as precipitating agent and added drop wise into zinc nitrate solution under vigorous stirring. Finally, after collecting, the resulting white precipitates $(\mathrm{ZnO})$ were centrifuged for $10 \mathrm{~min}$. Then, nanoparticles washed with distilled water several times to remove any impurities or possible ionized ions. The obtained precipitate was calcinated at $500^{\circ} \mathrm{C}$ for $3 \mathrm{hr}$ in muffle furnace. The chemical reaction between zinc nitrate and urea to precipitate the $\mathrm{ZnO}$ nanoparticles is as in the following equations:

$$
\begin{aligned}
& \mathrm{CO}\left(\mathrm{NH}_{2}\right)_{2}+\mathrm{H}_{2} \mathrm{O} \rightarrow \mathrm{CO}_{2}+2 \mathrm{NH}_{3} \\
& 2 \mathrm{NH}_{3}+\mathrm{H}_{2} \mathrm{O} \rightarrow 2 \mathrm{NH}_{4}^{+}+2 \mathrm{OH}^{-} \\
& \mathrm{Zn}\left(\mathrm{NO}_{3}\right)_{2} \rightarrow \mathrm{Zn}^{+2}+2 \mathrm{NO}_{3}^{-} \\
& \mathrm{Zn}^{+2}+2 \mathrm{OH}^{-} \rightarrow \mathrm{Zn}(\mathrm{OH})_{2} \stackrel{\Delta}{\longrightarrow} \mathrm{ZnO}+\mathrm{H}_{2} \mathrm{O}
\end{aligned}
$$

Chemical reaction of zinc oxide crystals formed by direct precipitation

Characterization of the $\mathrm{ZnO}$ nanoparticles

After preparation of nanoparticles, structure of samples was analyzed by certain techniques. To estimate the crystallite size, powder X-ray diffraction (XRD) was used (model: Bruker D8 advance X-ray powder diffractometer). Energy Dispersive X-ray Analysis (EDX) (FEI Company, Netherland) was performed to determine the zinc to oxygen ratio indicating purity of $\mathrm{ZnO}$. Transmission Electron Microscopy (TEM) (H800, Hitachi, Japan) also was used to measure particle size and morphology of the nanoparticles.

\section{Preparation of polyurethane nanocomposites}

PUF was prepared from $100 \%$ polyol and $100 \%$ isocyanate. Nanocomposites samples were prepared containing different concentrations of the nanofiller (g of nano $\mathrm{ZnO} / 100 \mathrm{ml}$ of PU matrix). Table 1 shows the formulations employed in this work. All the raw materials, except diisocyanate, were placed in a plastic beaker and the mixture was well stirred until complete homogenization. Then diisocyanate was added into the beaker with continuously stirring for about $12 \mathrm{~s}$ before foaming. The resulting mixture was immediately poured into an open mold to produce free-sized foam. After the preparation, the foams were put in an oven at $70^{\circ} \mathrm{C}$ for two hours and then left in air at room temperature and atmospheric pressure for three days to complete curing. Samples were 
cut after curing into specific shapes by certain cutter and then the different properties of the foams were characterized.

\section{Characterization of PU nanocomposites}

The morphology of the composites was studied under scanning electron microscope (SEM, Philips XL 30 microscope, U.S.A). Prior to the measurement, the specimens were coated with gold to provide an electrically conductive surface. It is used to observe the size of the foam cells for each sample. The mechanical properties of the PUF samples were performed at ambient condition with tensile testing machine (Model Z 010, Zwick, Germany). The tensile strength of three specimens per each sample was measured and the average of these values was reported. The density was calculated directly from the mass and geometric volume of the acoustic samples used. The absorption coefficient is a measure of the ability of a material to absorb sound. A material with an absorption coefficient of 1.0 indicates a purely absorbing material whereas a material with an absorption coefficient of 0 indicates that the material is purely reflective [16]. A two-microphone impedance tube was employed to obtain the noise reduction coefficient. The sample was placed inside a thin cylindrical Teflon sleeve and positioned against a rigid backing at one end of the impedance tube, while the other end of the tube was equipped with a sound source. A plane acoustic wave is generated by the sound source that propagates along the axis of the tube. Microphones placed along the length of the tube are used to detect the sound wave pressure transmitted to the sample and the portion of the wave that is reflected [17].

\section{$\underline{\text { Results and Discussion }}$}

Characterization of the synthesized $\mathrm{ZnO}$

Powder X-Ray diffraction (XRD) study

The XRD pattern of the synthesized $\mathrm{ZnO}$ powder is illustrated in Fig. 1. The peaks appeared

TABLE 1. Chemical compositions of polyurethane foam (PUF) blown by water.

\begin{tabular}{lc}
\hline \multicolumn{1}{c}{ Materials } & Composition \\
\hline Polyol & 50 \\
Diisocyanate & 50 \\
Distilled water & 3 \\
Nano Zinc oxide & $(0,0.25,0.5,1,2,3)$ \\
\hline
\end{tabular}

at $2 \theta$ range are of $31.67^{\circ}, 34.34^{\circ}, 36.19^{\circ}, 47.53^{\circ}$, $56.57^{\circ}, 62.66^{\circ}, 66.37^{\circ}, 67.9^{\circ}$, and $69.5^{\circ}$. The sharp diffraction peaks appeared in the figure indicates the good crystallinity of the nano $\mathrm{ZnO}$ prepared. The broading of the recorded peaks indicates the small crystalline size of the synthesized $\mathrm{ZnO}$. The average size of the particles was estimated by the $\mathrm{X}$-ray line-broading method using the scherrer equation:

$$
\tau=\frac{R \lambda}{\beta \operatorname{Cos} \theta}
$$

where, $\tau$ is the mean size of the crystalline, $\mathrm{R}$ is a dimensionless shape factor, with a value close to unity. The shape factor has value of about 0.9 , but varies with the actual shape of the crystallite. $\lambda$ is the X-ray wavelength. $\beta$ is the line broadening at half the maximum intensity, and $\theta$ is the diffraction angle.

From the XRD data, the average crystallite size of $\mathrm{ZnO}$ was found to be $21 \mathrm{~nm}$. No peaks of impurities are observed, indicating the formation of high purity of nano $\mathrm{ZnO}$, which was further confirmed by EDX.

\section{Energy dispersive $X$-ray spectrometry (EDX)}

The chemical stoichiometry of $\mathrm{ZnO}$ nanoparticle was investigated with EDX. This analysis was performed on three different areas randomly across the investigated sample to determine the zinc and oxygen ratio. From Fig. 2, only zinc and oxygen are detected indicating the high purity of the synthesized $\mathrm{ZnO}$. Quantitively the oxygen to zinc weight ratio was found 1 to 4, respectively, indicating the stoichiometric formation of $\mathrm{ZnO}$. The sharp diffraction peaks apparent in the figure indicate good crystallinity of the prepared nanoparticles.

Transmission electron microscopy analysis (TEM)

Figure 3 reveals the TEM image of $\mathrm{ZnO}$ nanoparticles obtained from aqueous precipitation. After calcination of the precipitate at $500^{\circ} \mathrm{C}$ for $3 \mathrm{hr}$, the $\mathrm{ZnO}$ nanoparticles were found in the average range of $27 \mathrm{~nm}$. It was observed that 


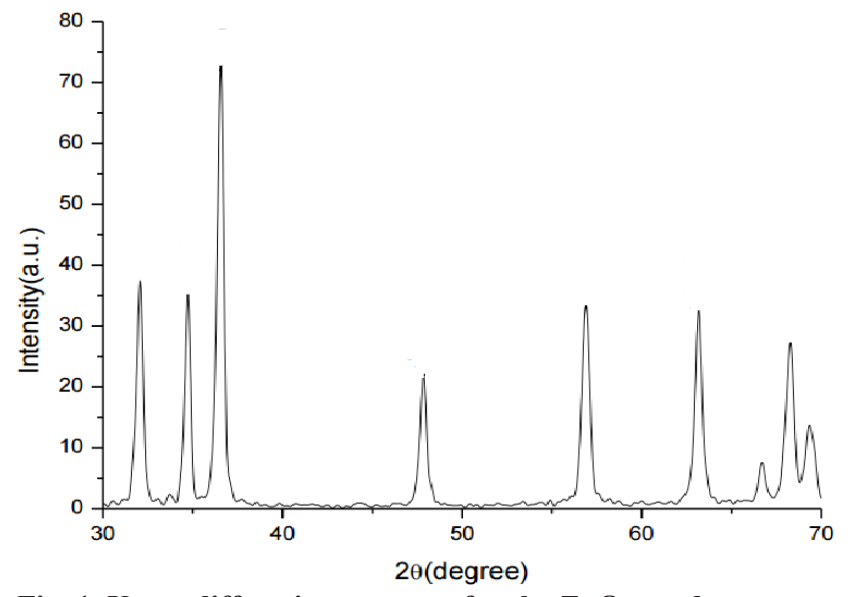

Fig. 1. X-ray diffraction patterns for the $\mathrm{ZnO}$ powder.

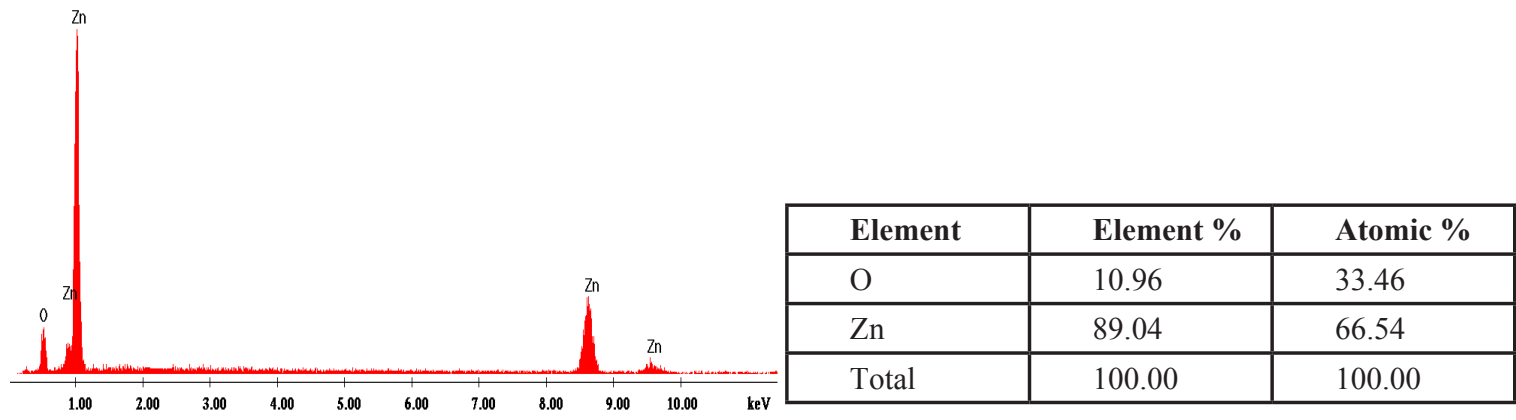

Fig. 2. EDX patterns of $\mathrm{ZnO}$ nanoparticles.

TABLE 2. Density of the PUF/ZnO with different concentrations.

\begin{tabular}{cl}
\hline Nano ZnO content (wt.\%) & $\begin{array}{l}\text { Density } \\
\left(\mathbf{K g} / \mathbf{m}^{3}\right)\end{array}$ \\
\hline 0 & $37.0 \pm 0.5$ \\
0.25 & $58.8 \pm 0.3$ \\
1 & $62.0 \pm 0.7$ \\
2 & $66.6 \pm 0.6$ \\
3 & $45.7 \pm 0.4$ \\
\hline
\end{tabular}

zinc oxide is in spherical shape and aggregated into clusters. These aggregates occurred probably during the calcinations process. This may be due to the large specific surface area and high surface energy of the nanoparticles [18].

\section{Morphology of the nanocomposites}

The SEM images of the pure PU and the PU/ $\mathrm{ZnO}$ nanocomposite with 0.25 and $0.5 \mathrm{wt} \%$ of $\mathrm{ZnO}$ contents is shown in Fig. 4. The foams have a cellular structure and consist of partially open cells with circular holes. From the micrograph analysis, a good dispersion of $\mathrm{ZnO}$ though the sample was achieved. The mean cell size of pure PU foam is decreased with addition of nanoparticles. The cell sizes were 430 and $330,305 \mu \mathrm{m}$ for $0,0.25$ and 0.5 wt. $\%$ of $\mathrm{ZnO}$, respectively. Figure $4 \mathrm{c}$ shows that some of cells overlap with each other and the particle size decrease further. This behavior is considered to be due to the opposing effect 


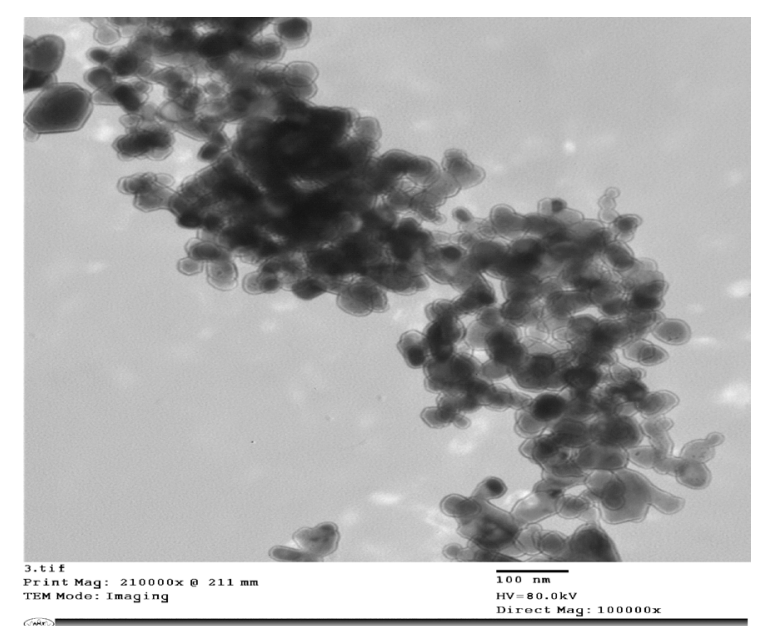

Fig. 3. TEM micrograph of nanosized $\mathrm{ZnO}$ at $500^{\circ} \mathrm{C}$.

of nanoparticle addition on nucleation and cell growth. The nanoparticles act as nucleation sites for cell formation and since a higher number of cells start to nucleate, but at the same time, the addition of $\mathrm{ZnO}$ seems to hinder the cell growth

a)

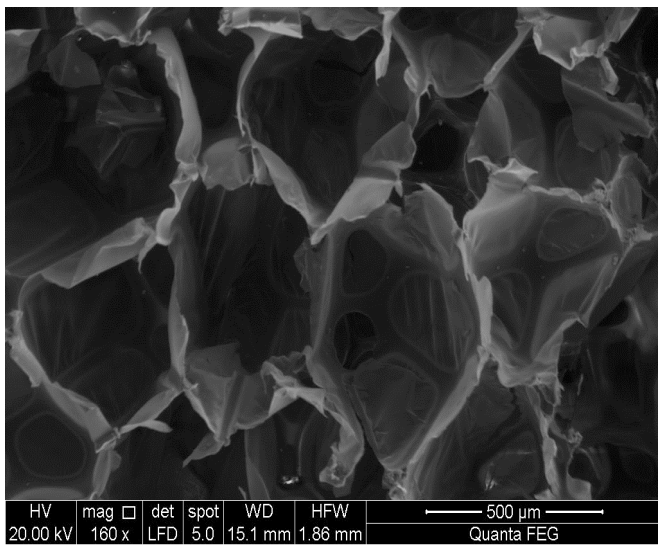

and results in smaller cell size compared with the pure PUF [19].

Density

The densities of the nanocomposite foam samples are shown in Table 2. The density of

b)

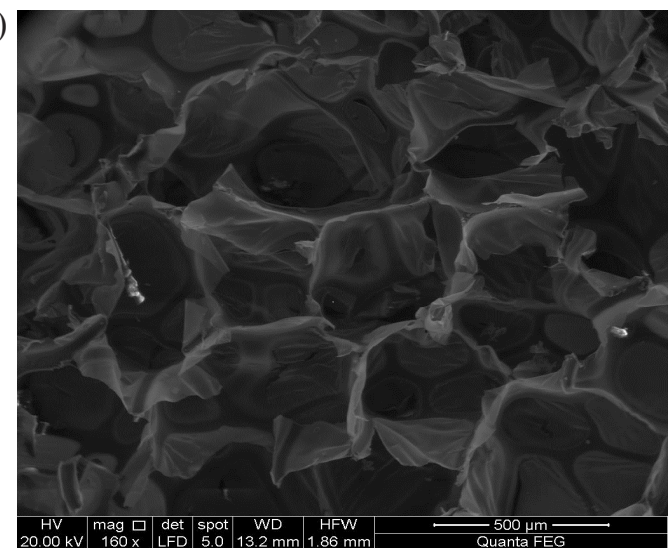

c)

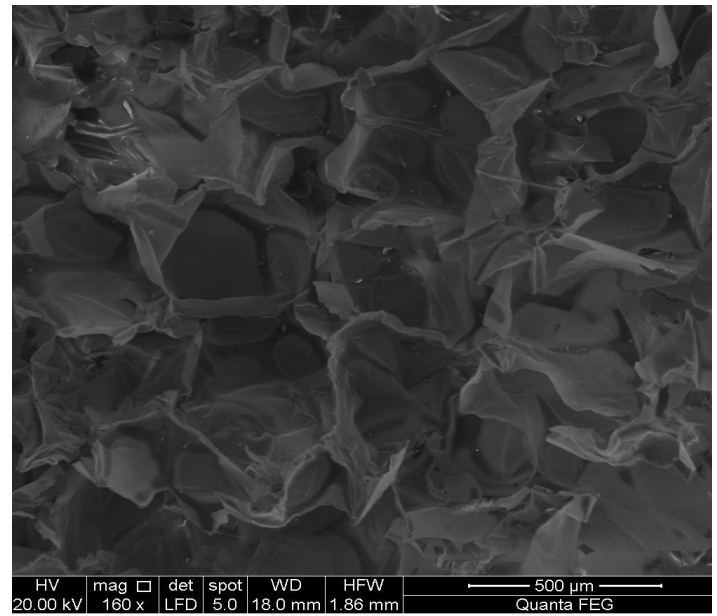

Fig. 4. Representative SEM of the $\mathrm{ZnO} / \mathrm{PU}$ foam perpendicular to the foaming direction (a) zero, (b) 0.25 , (c) 0.5 wt.\%. 
TABLE 3. Noise reduction coefficient for polyurethane with different additives.

\begin{tabular}{ccccccc}
\hline $\begin{array}{c}\text { Noise reduction coefficient } \\
(\mathbf{H z})\end{array}$ & \multicolumn{7}{c}{$\begin{array}{c}\text { Content of ZnO } \\
\text { (wt.\%) }\end{array}$} \\
\hline F & 0 & 0.25 & 0.5 & 1 & 2 & 3 \\
250 & 0.37 & 0.26 & 0.18 & 0.20 & 0.42 & 0.42 \\
500 & 0.48 & 0.32 & 0.25 & 0.26 & 0.51 & 0.51 \\
1000 & 0.51 & 0.37 & 0.30 & 0.34 & 0.62 & 0.63 \\
2000 & 0.57 & 0.41 & 0.35 & 0.46 & 0.71 & 0.63 \\
\hline
\end{tabular}

the pure PU foam was $39.96 \mathrm{Kg} / \mathrm{m}^{3}$. The density increases to $58.8,62.02$ and 62.7 with the addition of $0.25,0.5$ and $1 \mathrm{wt} . \%$ of nanoparticles additions, respectively, then decreases again with further additions. This behavior is due to the opposing effect of nanoparticle addition on nucleation and cell growth. The nanoparticles act as nucleation sites promoting the formation of a higher quantity of bubbles. This tends to increase with the increasing nanoparticles content, up to $1 \mathrm{wt} . \%$. But at the same time, growth of the resulted cells seems to be hindered by the farther increase in nanoparticles content, 2 and 3 wt. $\%$. The increase in density with decrease in the cell size when nanoparticles are added to the PU foam has been reported by several authors [20].

\section{Mechanical properties}

Figure 5 shows the mechanical properties of polyurethane with different contents of $\mathrm{ZnO}$. The tensile strength of polyurethane foam is $4.2 \mathrm{~N} /$ $\mathrm{cm}^{2}$, the elongation is $20.63 \%$. Introduction of the $\mathrm{ZnO}$ up to $1 \mathrm{wt} . \%$ to polyurethane results in the increase of tensile and decrease the elongation.
Addition of larger amounts of the filler causes decrease of these parameters. The increase of tensile strength is associated to the decreased elongation of the polymer. This is corresponding to the strong adhesion between the filler particles and the matrix, as proved by SEM. When the content is over $1 \mathrm{wt} . \%$, the agglomeration of $\mathrm{ZnO}$ particles decreases the values of the mechanical parameters.

\section{Sound properties}

To determine the effect of addition nanozinc oxide of polyurethane foam on the sound transmission loss, TL, we should measure the density for each sample where the mass of the wall is a main parameter affecting TL of the wall. This mass law predicts that doubling the mass per unit area or the frequency increases TL. Hence, TL can be calculated by the following equation [21]:

$$
\pi L=20 \log (\mathrm{mf})-20 \log \left(\frac{P_{o} \mathrm{c}}{\pi}\right)
$$

where $\mathrm{m}, \rho_{0}$ and $\mathrm{c}$ are the mass per unit area, air density and sound velocity in air, respectively.

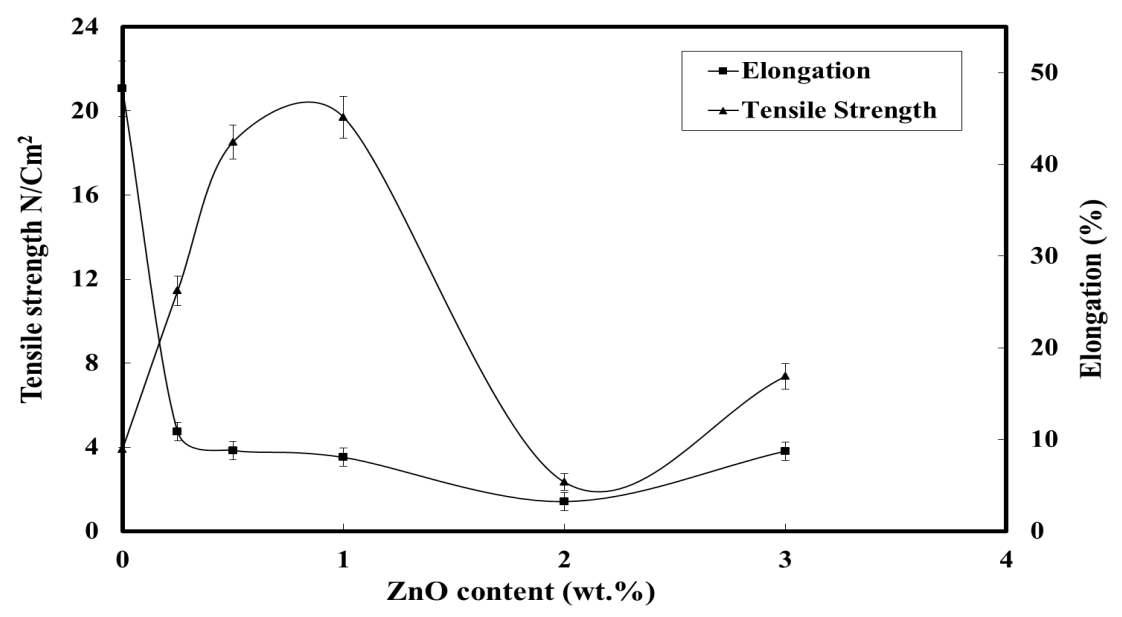

Fig. 5. Mechanical parameters of polyurethane filled with nanozinc oxide. 
Figure 6 shows the relation between the calculated sound transmission loss (TL) and the frequency for the polyurethane foam at different contents of nanozinc oxide from $0 \mathrm{wt} . \%$ to $3 \mathrm{wt} . \%$. The figure illustrates that the sound transmission loss, TL was increased with an increase in the percentage amount of nanozinc oxide from $0 \mathrm{wt} . \%$ to $1 \mathrm{wt} . \%$, then tends to decrease by adding $2 \mathrm{wt} . \%$ of nanozinc oxide and finally started to increase a little bit for the amount 3 wt.\% of nanozinc oxide. The maximum sound transmission loss, TL is obtained with 1 wt.\% for all frequencies. This means that an amount of nanozinc oxide within a certain range has a significant effect on controlling the pore size and density of the polyurethane foam. The general behavior showed an increase of sound transmission loss, TL values in all frequency range.

In addition to the sound transmission loss, the performance of sound absorber materials is evaluated by the sound absorption coefficient and is usually expressed as a decimal varying between 0 and 1.0. In other words, the absorber material is characterized by its value of the sound absorption coefficient $(\alpha)$ as a function of frequency. The noise reduction coefficient (NRC) which represents a single number, defined as the average value of the absorption coefficient of a material at frequencies 250, 500, 1000 and $2000 \mathrm{~Hz}$.

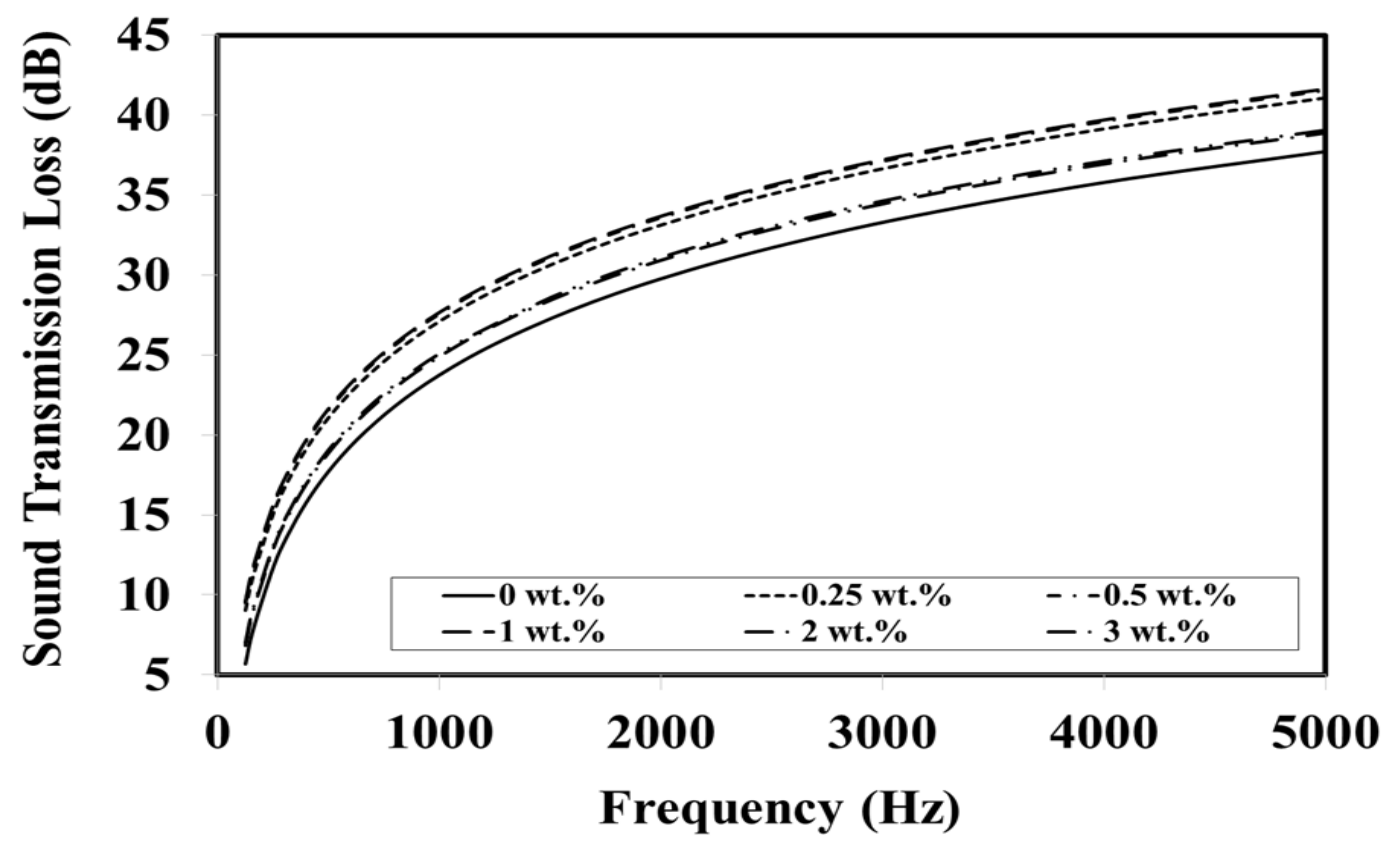

Fig. 6. Sound transmission loss of polyurethane filled with nanozinc oxide

Noise reduction coefficient of polyurethane foam with different concentrations of nanozinc oxide is shown in Table 3. From this table, one notices that the NRC at each frequency decreases as the amount of nanozinc oxide increases to $0.5 \mathrm{wt} \%$ and started to increase for other amounts (1 wt.\%, 2 wt.\% and 3 wt.\%) under investigation. These results agree somehow with the results obtained by sound transmission loss. The standard uncertainty of dispersion of sound reduction index and sound transmission loss versus frequency were calculated during measurements according to the international standard [17]. The influence of specimen size, number of source positions, and microphone positions have included in the calculations of standard uncertainty of sound absorption coefficient in the measurement tube. The standard uncertainty of dispersion of each sample ranged from 0.003 to 0.010 in frequency range from 125 to $5000 \mathrm{~Hz}$.

\section{Conclusion}

Polyurethane nanocomposite foam samples with zinc oxide in different concentrations were prepared and their properties were evaluated. The results were compared with the neat sample without addition of filler. From XRD and TEM analyses, the average size of the prepared $\mathrm{ZnO}$ powder was approximately $24 \mathrm{~nm}$. The density of the foam changed due to the opposing effect 
of nanoparticle addition, which proved by morphology. The increase density and decrease the cell size depended on the amount of $\mathrm{ZnO}$ addition to PUF. Addition of zinc oxide nanofiller up to $1 \mathrm{wt} . \%$ to polyurethane results in the increase of tensile strength and decrease of the elongation. Further addition, these parameters were decreased. In this research, PU foams with different amounts of nano zinc oxide were used to enhance the sound absorption properties. To show the effect of the various additive components on the sound absorption of the foams, the correlations between the contents of additive component and absorption coefficients were held. In general, the nano Zinc oxide has a clear effect on the sound damping properties.

\section{References}

1. Wang Z. L., Song J., Piezoelectric Nanogenerators Based on Zinc Oxide Nanowire Arrays. Science, 312, 242-246 (2006).

2. Look D. C., Recent Advances in $\mathrm{ZnO}$ Materials and Devices. Materials Science and Engineering: $B, \mathbf{8 0}, 383-387$ (2001).

3. Yang Y., Chen H., Zhao B., Bao X., Size Control of Zno Nanoparticles via Thermal Decomposition of Zinc Acetate Coated on Organic Additives. $J$. Cryst. Growth, 263, 447-453 (2004).

4. Lee J. H., Ko K. H., Park B. O., Electrical and Optical Properties of ZnO Transparent Conducting Films by the Sol-Gel Method. Journal of Crystal Growth, 247, 119-125 (2003).

5. Ayouchi R., Leinen D., Martin F., Gabas M., Dalchiele E., Ramos-Barrado J. R., Preparation and Characterization of Transparent of $\mathrm{ZnO}$ Thin Films Obtained by Spray Pyrolysis. Thin Solid Films, 426, 68-77 (2003).

6. Wu C. F., Yanagishi T. A., Nakamoto Y., Ishida S., Nitta K. H., Kubota S., Organic Hybrid of Chlorinated Polyethylene and Hindered Phenol. I. Dynamic Mechanical Properties. Journal of Polymer Science Part B: Polymer Physics, 38, 2285-295 (2000).

7. Theocaris P. S., Spathis G. D, Glass-Transition Behavior of Particle Composites Modeled on the Concept of Interphase. Journal of Applied Polymer Science, 27, 3019-3025 (1982).

8. Klempner D, Frisch KC, Handbook of Polymeric Foams and Foam Technology. Hanser publications (1991).

9. Latinwo G. K., Aribike D. S., Susu A.A., Kareem S. A., Effects of Different Filler Treatments on the Morphology and Mechanical Properties of
Flexible Polyurethane Foam Composites. Nature and Science, 8, 23-26 (2010).

10. Xu R., Manias E., Synder A. J., Runt J., New Biomedical poly(urethane-urea)- Layered silicate Nanocomposites. Macromolecules, 34, 337-339 (2001).

11. Chang J. H., An Y. U., Nanocomposites of Polyurethane with Various Organoclays: Permeability. Journal of Polymer Science: Part B: Polymer Physics, 40, 670-677 (2002).

12. Liliana M., Ryszard P., Alan C., Jennifer M. N., Processing and Characterization of Polyurethane Nanocomposite Foam Reinforced With Montmorillonite-Carbon Nanotube Hybrids. Composite Part A Applied Science and Manufacturing, 44, 1-7 (2013).

13. Cigdem C., Elif D., Idris G., Hulya C., Flexural Behaviours of Nanophased Rigid Polyurethane Foam Core Sandwich Composites. 21 $1^{\text {st }}$ International Conference on Composite Materials, 20-25 ${ }^{\text {th }}$ August (2017).

14. Benni R., Onny U., Maxwell N., Rigid Polyurethane Nanocomposites Prepared by direct Incorporation: Effects of Nanoclay, Carbon Nanotubes and Mixing Speed on Physical and Morphological Properties. Materials Science and Engineering, 319, 1-8 (2018).

15. Bagheri S., Chandrappa K. G., Abd Hamid S. B., Facile Synthesis of Nano-Sized $\mathrm{ZnO}$ by Direct Precipitation Method. Der Pharma Chemica, 5, 265-270 (2013).

16. Neithalath N., Wesis W. J., Olek J., Acoustic Absorption Behavior of Fiber Reinforced Enhanced Porosity Concrete. 550 Stadium Mall Drive, West Lafayette, Indiana, USA-47907.

17. ISO 10534, Determination of Sound Absorption Coefficient and Impedance in Impedance Tubes. Acoustics (1998).

18. Wacharawichanant S., Thongyai S., Phutthaphan A., Effect of Particle Sizes of Zinc Oxide on Mechanical, Thermal and Morphological Properties of Polyoxymethylene/Zinc Oxide Nanocomposites. Polymer Test Journal, 27, 971976 (2008).

19. Madaleno L., Norman J., Proccessing and characterization of polyurethane nanocomposite foam reinforced with montmorillonite-carbon nanotube hybrids. Composites Part A: Applied Science and Manufacturing, 44, 1-7 (2013).

20. Piszczyk L., Danowska M., MietlarekKropidlowska A., Szyszka M., Strankowski M., Synthesis and Thermal Studies of Flexible Polyurethane Nanocomposite Foams Obtained

Egypt. J. Chem. 62, No. 2 (2019) 
Using Nanoclay Modified with Flame Retardant Compound. Journal of Thermal Analysis and Calorimetry, 118, 901-909 (2014).

21. Yan J., Lee C., Lee C. W., Kang D.W, Ahn S, H., Soundproof Effect of Nanoclay Reinforced
Polypropylene Composites, The 18th International Conference on Composite Materials, Jeju, Korea (2011).

(Received 1/8/2018; accepted 27/9/2018)

\section{تجهيز مركب البولي يوريثان المقوى بأكسيد الزنك المتناهي في الصغر للتطبيقات الصوتية

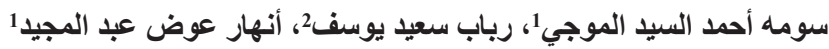

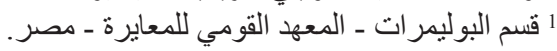

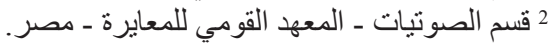

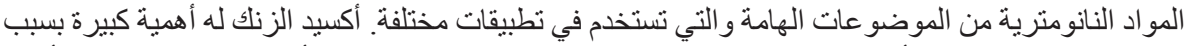

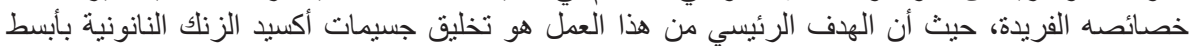

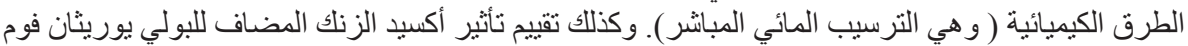

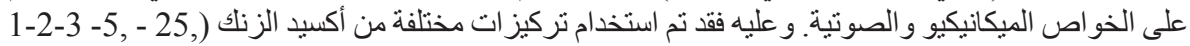

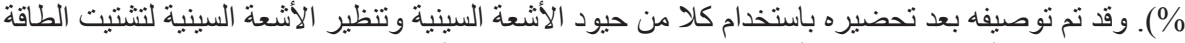

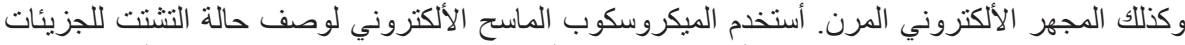

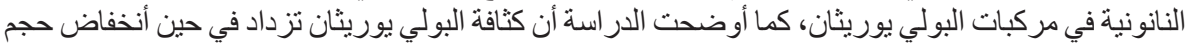

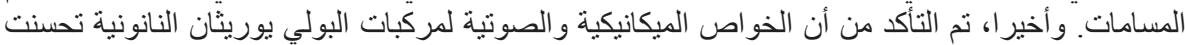
بأضافة أكسيد الزنك وتعتمد قيمة الخو اص تص على الكمية المضافه منها. 